\title{
Brainstem involvement in the initial response to pain
}

\author{
Predrag Petrovic, ${ }^{\mathrm{a}, *}$ Karl Magnus Petersson, ${ }^{\mathrm{a}}$ Per Hansson, ${ }^{\mathrm{b}}$ and Martin Ingvar ${ }^{\mathrm{a}}$ \\ a PET-Cognitive Neurophysiology, Department of Clinical Neuroscience, Karolinska Insitute, 17176 Stockholm, Sweden \\ ${ }^{\mathrm{b}}$ Neurogenic Pain Unit, Multidisciplinary Pain Centre and Department of Rehabilitation Medicine, Karolinska Hospital, Karolinska Institute, \\ 17176 Stockholm, Sweden
}

Received 11 June 2003; revised 26 January 2004; accepted 26 January 2004

Available online 6 May 2004

\begin{abstract}
The autonomic responses to acute pain exposure usually habituate rapidly while the subjective ratings of pain remain high for more extended periods of time. Thus, systems involved in the autonomic response to painful stimulation, for example the hypothalamus and the brainstem, would be expected to attenuate the response to pain during prolonged stimulation. This suggestion is in line with the hypothesis that the brainstem is specifically involved in the initial response to pain. To probe this hypothesis, we performed a positron emission tomography (PET) study where we scanned subjects during the first and second minute of a prolonged tonic painful cold stimulation (cold pressor test) and nonpainful cold stimulation. Galvanic skin response (GSR) was recorded during the PET scanning as an index of autonomic sympathetic response. In the main effect of pain, we observed increased activity in the thalamus bilaterally, in the contralateral insula and in the contralateral anterior cingulate cortex but no significant increases in activity in the primary or secondary somatosensory cortex. The autonomic response (GSR) decreased with stimulus duration. Concomitant with the autonomic response, increased activity was observed in brainstem and hypothalamus areas during the initial vs. the late stimulation. This effect was significantly stronger for the painful than for the cold stimulation. Activity in the brainstem showed pain-specific covariation with areas involved in pain processing, indicating an interaction between the brainstem and cortical pain networks. The findings indicate that areas in the brainstem are involved in the initial response to noxious stimulation, which is also characterized by an increased sympathetic response.

(C) 2004 Elsevier Inc. All rights reserved.
\end{abstract}

Keywords: Positron emission tomography; Regional cerebral blood flow; Brainstem; Pain

\section{Introduction}

Supraspinal processing of pain has been divided between processes in brainstem networks and in the cortex (Price, 2000). Although these systems are highly interactive, it has been postulated that they can be more or less involved in different phases of

* Corresponding author. Section of Clinical Neurophysiology, Department of Clinical Neuroscience, Karolinska Hospital, Cognitive Neurophysiology R2-01, 17176 Stockholm, Sweden. Fax: +46-8-51773266.

E-mail address: predrag.petrovic@ks.se (P. Petrovic).

Available online on ScienceDirect (www.sciencedirect.com.) pain processing. While the brainstem seems to be more important in the immediate pain response, higher order regions seem to be more involved in the later response (Price, 2000).

However, the brainstem mediates a response to a complex situation, which may not just consist of pain. Instead, it is a way for the organism to rapidly cope in a life-threatening situation with a set of prepackaged behaviors to increase the chance for survival (Bolles, 1970; Fanselow, 1994; Timberlake, 1993). These states have been described for experimental animals both in encounters with predators (Blanchard et al., 1990; Fanselow and Sigmundi, 1986) but also elicited by noxious stimulation (Fanselow, 1982), for example, the dorsolateral periaqueductal grey (PAG) may independently of cortical networks increase autonomic responses, induce flight or fight behaviors, and nonopioid analgesia in direct response to noxious stimulation. Thus, it may be proposed that the dorsolateral PAG is involved in the initial response to noxious input that also includes an autonomic response (Fanselow, 1994).

It is unlikely that the dorsolateral PAG is the only brainstem region involved in this response. Several other brainstem nuclei, such as the parabrachial nucleus, the locus coeruleus, and the hypothalamus, also receive direct nociceptive information from the spinobulbar tract (Craig and Dostrovsky, 1999). These regions interact with a more elaborate brainstem network that may both modulate cortical and spinal processing (Craig and Dostrovsky, 1999; Fields and Basbaum, 1999; Parvizi and Damasio, 2001).

The studies presented above are in line with the known relationship between acute pain and the sympathetic response on a behavioral level in human subjects (Gracely, 1999; Jäning, 1995). The idea that the brainstem is more involved in the initial pain response may explain habituation of the autonomic responses during tonic pain (Lovallo, 1975) although the subjective pain ratings increase or remain equal (Rainville et al., 1992; Tassorelli et al., 1995). Brain systems involved in the autonomic response during pain should therefore attenuate their activity during prolonged painful stimulation, while other regions participating in the processing of pain intensity and unpleasantness should increase in activity or at least remain equally activated during the prolonged pain. Thus, stimulus duration should have an opposite effect on brainstem vs. cortical activity during the processing of nociceptive signals. To test this hypothesis, we performed a PET study where we scanned different time components in prolonged painful cold 
stimulation and nonpainful cold stimulation. A rapid communication from the same data set on the S1 functional connectivity has previously been published (Petrovic et al., 2002b).

\section{Material and methods}

\section{Experimental design}

Seven subjects were included in the study (males, right handed, 20-35 years). No neurological or psychiatric illness was present according to the interviews. The study was approved by the ethical committee at the Karolinska Hospital.

Twelve measurements of the regional cerebral blood flow (rCBF) were made in each subject using a 3D Ecat Exact HR positron emission tomograph (PET) and bolus injections of 500 MBq [ $\left[{ }^{15} \mathrm{O}\right]$ butanol (Berridge et al., 1990; Ingvar et al., 1994; Wienhard et al., 1994). The tracer was injected in a vein in the nonstimulated arm in each subject. The time from the tracer injection to the arrival of the bolus to the head was approximately
$10 \mathrm{~s}$ and was followed by a 1-min tracer uptake scan. A plaster head support was used to minimize head movements during the PET imaging. The subjects had their eyes open and fixated on a cross during each stimulation period.

$\mathrm{rCBF}$ was measured in four different conditions (Fig. 1A):

- Pain during approximately the first minute of cold pressor test (pa): The left hand was immersed in circulating water with glycol with a temperature of $0-0.5^{\circ} \mathrm{C}$ (cold pressor test) starting immediately after the tracer injection. Approximately $10 \mathrm{~s}$ after the stimulation onset, the scanning period started and continued for $1 \mathrm{~min}$. The subjects kept their hand in the painful water during one more minute after the scanning session was finished, that is, totally $2 \mathrm{~min}$ and $10 \mathrm{~s}$.

- Cold during approximately the first minute of nonpainful cold water bath (ca): As described above; however, the left hand was immersed in circulating water with a temperature of $20 \pm$ $0.5^{\circ} \mathrm{C}$.

- Pain during approximately the second minute of cold pressor test $(\mathrm{pb})$ : The left hand was immersed in circulating water with

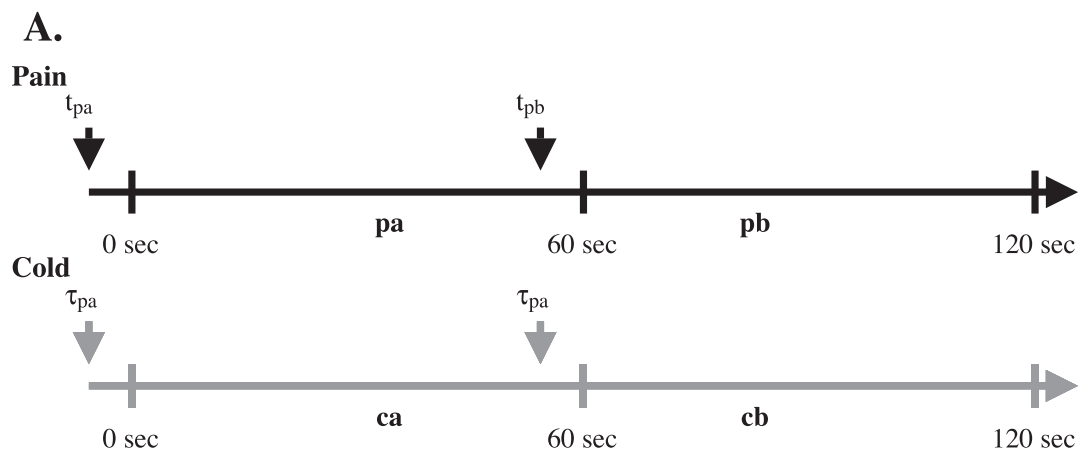

B.

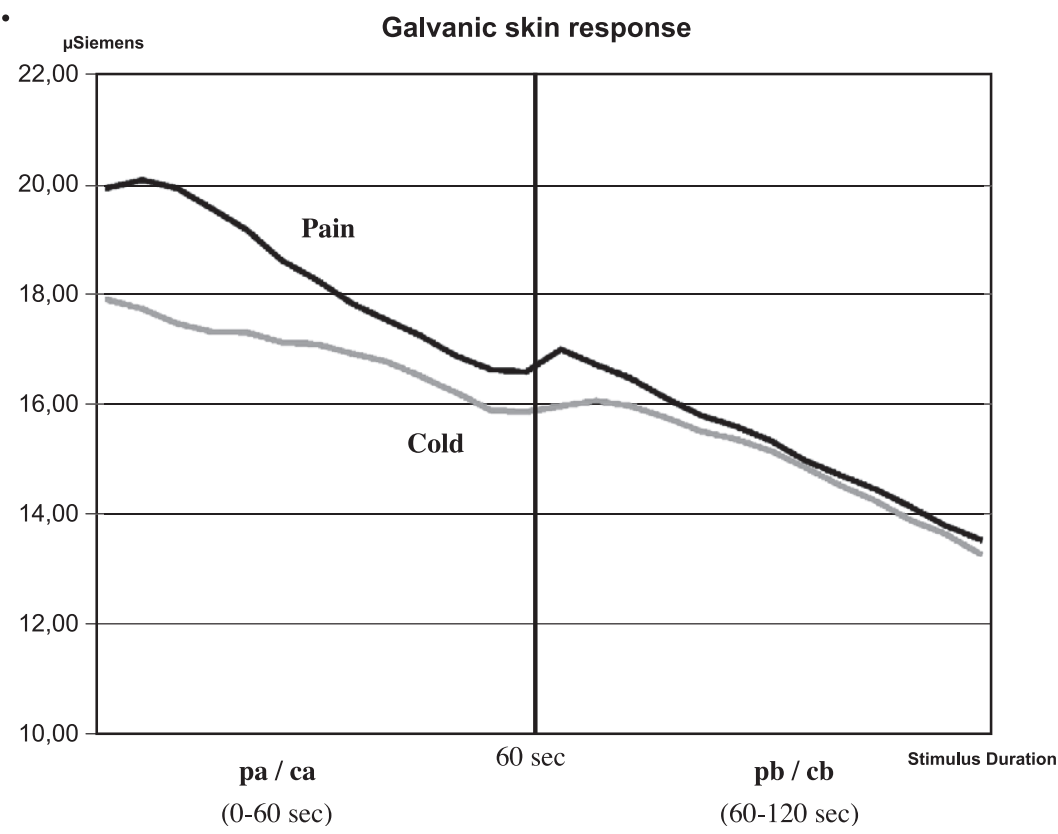

Fig. 1. (A) The experimental setting. The noxious stimulation (pa and pb) or the control cold stimulation (ca and cb) was always approximately 2 min of duration. The pa and ca conditions were scanned approximately during the first minute of stimulation. The pb and cb conditions were scanned approximately during the second minute of stimulation. The tracer for the initial pa and ca conditions $\left(t_{\mathrm{pa}}\right.$ and $\left.t_{\mathrm{ca}}\right)$ and for the later $\mathrm{pb}$ and $\mathrm{cb}$ conditions $\left(t_{\mathrm{pb}}\right.$ and $\left.t_{\mathrm{cb}}\right)$ was injected approximately $10 \mathrm{~s}$ before each condition started. There was an initial stimulation of $10 \mathrm{~s}$ before the experimental timing started (-10 tp $0 \mathrm{sec}$ ). (B) The GSR showed a habituation effect during the 2 min of stimulation. 
glycol with a temperature of $0-0.5^{\circ} \mathrm{C}$ (cold pressor test) for 2 min and $10 \mathrm{~s}$. After $1 \mathrm{~min}$ of stimulation onset, the tracer was injected and the 1-min scanning period started approximately $10 \mathrm{~s}$ later.

- Cold during approximately the second minute of nonpainful cold water-bath $(\mathrm{cb})$ : Same as $(\mathrm{pb})$ but with a water temperature of $20 \pm 0.5^{\circ} \mathrm{C}$.

The 12 scans were pseudorandomized in three blocks, that is, one of each condition was randomly included in every group of four scans. Thus, all of the three subgroups of scans contained conditions 1-4. The subjects were informed before each scan about the new condition. The interscan interval was 10-12 min, allowing the measured radioactivity from the subject to decline to background radiation level and for the pain and hand temperature to return to baseline.

After each stimulation period, the subjects rated the average pain intensity using a visual analogue scale (VAS). Zero equaled no pain intensity at all and 100 equaled the highest imaginable pain intensity.

The galvanic skin response (GSR) was measured as an index of sympathetic response and habituation during the pain and the cold conditions. Two electrodes with electrodermal gel were applied to the plantar surface of the left foot (approximately $1 \mathrm{~cm}$ apart) and connected to an in-lab constructed device measuring the GSR (in $\mu$ Siemens $(\mu S))$. The filtered analogue GSR was recorded online and an average response was calculated for the first and the second 60 -s period of the 120 -s stimulation following the first $10 \mathrm{~s}$ of stimulation. The functionality of each individual GSR measurement was verified with an unexpected, short-lasting loud sound before the first PET session, showing the expected GSR response in each subject. There was a 15 -min rest period (with a complete darkness and quietness) before the first PET scan and a similar 3min rest period before every new PET measurement to reach a relaxed rest state before every new session.

\section{Data analysis and statistics}

The PET images were realigned, spatially normalized, 3D Gaussian filtered (FWHM $=16 \mathrm{~mm}$ ) and modeled with the general linear model using the SPM99 software (Friston et al., 1995) (http://www.fil.ion.ucl.ac.uk/spm/). The PET data were proportionally scaled to account global confounders (e.g., variations in injected radioactive dose) and the global CBF activity was set to $50 \mathrm{U} / 100 \mathrm{~g} / \mathrm{min}$.

First, the rCBF increases and decreases were studied for pain during the first and second minute, $[(\mathrm{pa}-\mathrm{ca})$ and $(\mathrm{ca}-\mathrm{pa})]$ and $[(\mathrm{pb}-\mathrm{cb})$ and $(\mathrm{cb}-\mathrm{pb})]$, and for the main effect of pain, [(pa + $\mathrm{pb})-(\mathrm{ca}+\mathrm{cb})$ and $(\mathrm{ca}+\mathrm{cb})-(\mathrm{pa}+\mathrm{pb})]$. The $\mathrm{rCBF}$ changes that depended on stimulus duration were also studied for painful cold

Table 1

Altered activity in the predefined search area in the main effect of pain contrast and the stimulus duration contrasts

\begin{tabular}{|c|c|c|c|c|c|c|}
\hline Region & Contralateral $(X Y Z)$ & $Z$ value & Corrected $P$ value & 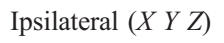 & $Z$ value & Corrected $P$ value \\
\hline \multicolumn{7}{|c|}{ Main effect of pain $(p a+p b)-(c a+c b)$} \\
\hline \multicolumn{7}{|c|}{ Increases $(\mathrm{pa}+\mathrm{pb})-(\mathrm{ca}+\mathrm{cb})$} \\
\hline \multirow[t]{5}{*}{$\mathrm{ACC}$} & $18-2042$ & 4.91 & $<0.001$ & -81824 & 3.53 & 0.05 \\
\hline & $10-1028$ & 4.58 & $<0.001$ & & & \\
\hline & 182424 & 4.26 & 0.001 & & & \\
\hline & 14034 & 4.11 & 0.001 & & & \\
\hline & 181430 & 3.82 & 0.002 & & & \\
\hline \multirow[t]{2}{*}{ Midanterior insula } & 30416 & 4.30 & 0.001 & & & \\
\hline & $344-2$ & 4.07 & 0.001 & & & \\
\hline Thalamus & $14-84$ & 5.83 & $<0.001$ & $-16-80$ & 3.90 & 0.002 \\
\hline \multirow[t]{2}{*}{ Cerebellum } & $2-62-22$ & 5.70 & $<0.001$ & $-20-48-32$ & 5.04 & $<0.001$ \\
\hline & $8-36-36$ & 3.34 & 0.009 & & & \\
\hline \multicolumn{7}{|c|}{ Decreases $(\mathrm{ca}+\mathrm{cb})-(\mathrm{pa}+\mathrm{pb})$} \\
\hline \multirow[t]{4}{*}{$\mathrm{S} 1 / \mathrm{PPC}$} & & & & $-46-3450$ & 5.91 & $<0.001$ \\
\hline & & & & $-2-3652$ & 5.04 & $<0.001$ \\
\hline & & & & $-8-2450$ & 4.99 & $<0.001$ \\
\hline & & & & $-14-2666$ & 4.56 & $<0.001$ \\
\hline Ant MTL/amygdala & $28-16-24$ & 4.41 & $<0.001$ & $-24-14-22$ & 4.96 & $<0.001$ \\
\hline \multirow[t]{2}{*}{$\mathrm{Obfc} / \mathrm{Tpc}$} & $3610-36$ & 4.00 & $<0.001$ & $-4430-4$ & 4.96 & $<0.001$ \\
\hline & & & & $-3614-30$ & 4.73 & $<0.001$ \\
\hline \multicolumn{7}{|c|}{ Main effect of stimulus duration } \\
\hline \multicolumn{7}{|c|}{ Initial activity $(\mathrm{pa}+\mathrm{ca})-(\mathrm{pb}+\mathrm{cb})$} \\
\hline Hypothalamus & $0-14-8$ & 3.98 & 0.040 & $-6-26-34$ & 3.85 & 0.040 \\
\hline \multicolumn{7}{|l|}{ Pons } \\
\hline \multicolumn{7}{|c|}{ Effect of stimulus duration during pain } \\
\hline \multicolumn{7}{|c|}{ Initial activity_pain $(\mathrm{pa}-\mathrm{pb})$} \\
\hline Hypothalamus & & & & $-2-16-8$ & 3.8 & 0.012 \\
\hline Pons & & & & $-6-28-34$ & 4.49 & 0.011 \\
\hline \multicolumn{7}{|c|}{ Interaction } \\
\hline \multicolumn{7}{|c|}{ Initial activity-pain $(\mathrm{pa}-\mathrm{pb})-(\mathrm{ca}-\mathrm{cb})$} \\
\hline Pons & $4-26-30$ & 2.85 & $0.035^{\mathrm{a}}$ & $-6-32-32$ & 3.0 & $0.036^{\mathrm{a}}$ \\
\hline
\end{tabular}

$\mathrm{ACC}=$ anterior cingulate cortex; Ant MTL = anterior medial temporal lobe; Obfc = orbitofrontal cortex; $\mathrm{PPC}=$ posterior parietal cortex; $\mathrm{S} 1=$ primary somatosensory cortex; $\mathrm{Tpc}=$ temporopolar cortex

${ }^{a}$ FDR corrected after masking. 
Table 2

Post hoc analysis of stimulus duration effect after $8 \mathrm{~mm}$ smoothing of the PET images

\begin{tabular}{|c|c|c|c|c|}
\hline Region & $\begin{array}{l}\text { Contralateral } \\
(X Y Z)\end{array}$ & $Z$ value & $\begin{array}{l}\text { Ipsilateral } \\
(X Y Z)\end{array}$ & $Z$ value \\
\hline \multicolumn{5}{|c|}{$\begin{array}{l}\text { Main effect of stimulus duration } \\
\text { Initial activity }(\mathrm{pa}+\mathrm{ca})-(\mathrm{pb}+\mathrm{cb})\end{array}$} \\
\hline Hypothalamus & & & $\begin{array}{l}2-18-8 \\
0-8-10\end{array}$ & $\begin{array}{l}4.34 \\
3.24\end{array}$ \\
\hline Medial thalamus & $-4-164$ & 4.02 & $10-62$ & 3.45 \\
\hline Pons & $\begin{array}{l}-6-26-38 \\
-10-22-20\end{array}$ & $\begin{array}{l}4.16 \\
3.54\end{array}$ & & \\
\hline \multicolumn{5}{|c|}{$\begin{array}{l}\text { Effect of stimulus duration during pain } \\
\text { Initial activity - pain }(\mathrm{pa}-\mathrm{pb})\end{array}$} \\
\hline Hypothalamus & $-2-18-8$ & 3.95 & & \\
\hline $\begin{array}{l}\text { Medial thalamus } \\
\text { Pons }\end{array}$ & $-4-1212$ & 3.27 & $\begin{array}{l}14-208 \\
0-26-32\end{array}$ & $\begin{array}{l}3.27 \\
3.83\end{array}$ \\
\hline \multicolumn{5}{|c|}{$\begin{array}{l}\text { Effect of stimulus duration during cold } \\
\text { Initial activity - cold }(\mathrm{ca}-\mathrm{cb})\end{array}$} \\
\hline $\begin{array}{l}\text { Medial thalamus } \\
\text { Pons }\end{array}$ & $\begin{array}{l}-4-162 \\
-10-26-18 \\
-4-28-40\end{array}$ & $\begin{array}{l}2.90(\mathrm{~ns}) \\
3.00(\mathrm{~ns}) \\
2.33(\mathrm{~ns})\end{array}$ & $10-82$ & 3.38 \\
\hline \\
\hline \multicolumn{5}{|c|}{ Initial activity-pain $(\mathrm{pa}-\mathrm{pb})-(\mathrm{ca}-\mathrm{cb})$} \\
\hline Pons & $\begin{array}{lll}-2 & -34 & -34 \\
-8 & -28 & -32\end{array}$ & $\begin{array}{l}3.13 \\
2.83\end{array}$ & & \\
\hline \multicolumn{5}{|c|}{$\begin{array}{l}\text { Conjunction analysis } \\
(\mathrm{pa}-\mathrm{pb}) \text { and }(\mathrm{ca}-\mathrm{cb})\end{array}$} \\
\hline Hypothalamus & $-2-6-12$ & 4.44 & & \\
\hline Medial thalamus & $-4-164$ & 4.44 & $10-164$ & 3.80 \\
\hline Pons & $-4-28-40$ & 3.72 & & \\
\hline
\end{tabular}

The search area was restricted to the brainstem area and surrounding regions; (ns) = nonsignificant activity.

and nonpainful cold [(ca - cb), $(\mathrm{cb}-\mathrm{ca}),(\mathrm{pa}-\mathrm{pb})$, and $(\mathrm{pb}-$ $\mathrm{pa})]$ and for the main effect of stimulus duration $[(\mathrm{pa}+\mathrm{ca})-(\mathrm{pb}+$ $\mathrm{cb})$ and $(\mathrm{pb}+\mathrm{cb})-(\mathrm{pa}+\mathrm{ca})]$. Finally, the interaction analysis of $[(\mathrm{pa}-\mathrm{pb})-(\mathrm{ca}-\mathrm{cb})]$ and $[(\mathrm{pb}-\mathrm{pa})-(\mathrm{cb}-\mathrm{ca})]$ were performed to study how the stimulus duration effects in pain differ from stimulus duration effects in cold in the same experimental setting.

To increase the sensitivity, only regions of a predefined pain matrix were studied. The predefined matrix was chosen based on previous functional neuroimaging studies of experimental pain (see further Ingvar, 1999) and included the primary and secondary somatosensory cortex (i.e., S1 and S2), insula, ACC, thalamus, amygdala, hypothalamus, brainstem, and orbitofrontal cortex. Activations in areas of BA43 and inferior parts of BA40 are called activations in somatosensory association areas rather than secondary sensory cortex (S2), when they also include the lateral parietal cortex (Petrovic et al., 2000). An increased activity in this matrix with a $Z$ score $>3.09$ (uncorrected $P$ value $<0.001)$ was regarded as significant. However, the false discovery rate (FDR) corrected $P$ values (Genovese et al., 2002) are also presented in Table 1. Coordinates and anatomical definitions of local maxima are given according to an approximate Talairach-Tournoux stereotactical space (Talairach and Tournoux, 1988).

In the interaction analysis, we tested whether regions that were differently activated by stimulus duration were specifically affected by the painful conditions. To reduce the search volume and increase the sensitivity of the interaction analysis, a mask- ing procedure of the interaction contrast was performed with the relevant contrasts. This procedure also assures that observed interactions were in the functionally defined matrix activated by the main effects of stimulus duration. The initial threshold was set to $Z=2.33$ and clusters of volume $\geq 10$ voxels with a maxima with $Z$ score $>2.56$ (uncorrected $P$ value $<0.005$ ) were accepted as significant for the predefined regions. Thus, $[(\mathrm{pa}-\mathrm{pb})-(\mathrm{ca}-\mathrm{cb})]$ was masked by the $[(\mathrm{pa}+\mathrm{ca})-$ $(\mathrm{pb}+\mathrm{cb})]$ matrix and $[(\mathrm{pb}-\mathrm{pa})-(\mathrm{cb}-\mathrm{ca})]$ was masked by the $[(\mathrm{pb}+\mathrm{cb})-(\mathrm{pa}+\mathrm{ca})]$ matrix. Only those predefined regions in the interaction analysis, which were significant after the masking procedure, are reported.

The $16 \mathrm{~mm}$ of smoothing is optimal for cortical regions. However, an important part of our interest was the brainstem for which a smaller smoothing may better separate the different activations. Therefore, a post hoc analysis was performed with 8$\mathrm{mm}$ smoothed images for illustrative purposes. These are separately presented in Table 2 and in the figure of brainstem activation (Fig. 3). As a part of this spatially more restricted analysis, also a conjunction analysis between the two simple main effect of stimulus duration, that is, $(\mathrm{ca}-\mathrm{cb})$ and $(\mathrm{pa}-\mathrm{pb})$, was performed to investigate whether both conditions contributed to the stimulus duration effect in the brainstem.

To further explore whether the stimulus-dependent regions covaried with other regions known to process pain, a functional connectivity analysis (Friston, 1994; Friston et al., 1997) was performed. The voxels showing the highest $Z$ score in $(\mathrm{pa}-\mathrm{pb})$
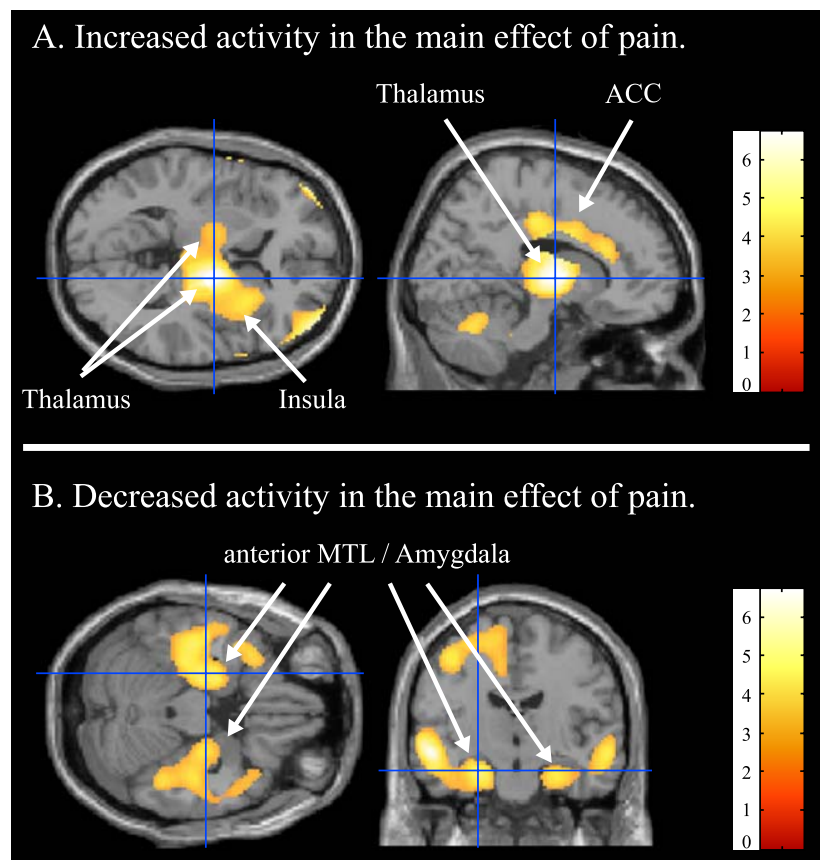

Fig. 2. (A) Areas that showed an increased activity in the main effect of pain $(\mathrm{pa}+\mathrm{pb})-(\mathrm{ca}+\mathrm{cb})$. The horizontal image shows increased activity in the contralateral thalamus (cross), the ipsilateral thalamus, and the contralateral insula. The sagittal view shows increased activity in the ACC and the contralateral thalamus (cross). (B) Regions that showed decreased activity during pain $(\mathrm{ca}+\mathrm{cb})-(\mathrm{pa}+\mathrm{pb})$. Both the sagittal and coronal image indicates decreased activity in the left (cross) and right anterior medial temporal lobe (MTL) or amygdala. The showed activity was thresholded at $Z=3.09$. The activity is presented on an SPM99 template. 
were used as a representation of that region and the adjusted activity was extracted for these voxels. The activity for each scan was then subtracted with the average activity for each condition, that is, average correction. These values were then used as covariates of interest for each of the four conditions ( $p a, p b$, ca, and $\mathrm{cb}$ ) in the SPM99 and the four conditions were modeled as confounding covariates. We then studied the covariation between the regions showing a significant stimulus duration effect and the regions in the predefined matrix during $\mathrm{pa}, \mathrm{pb}, \mathrm{ca}$, and $\mathrm{cb}$. We also studied differences between the regressions in the conditions by employing contrast analysis in the SPM99. Covariation results with a $Z$ score $>3.09$ (uncorrected $P$ value $<0.001$ ) were regarded as significant. Since this analysis was made to determine whether there were data indicating a general interaction between the
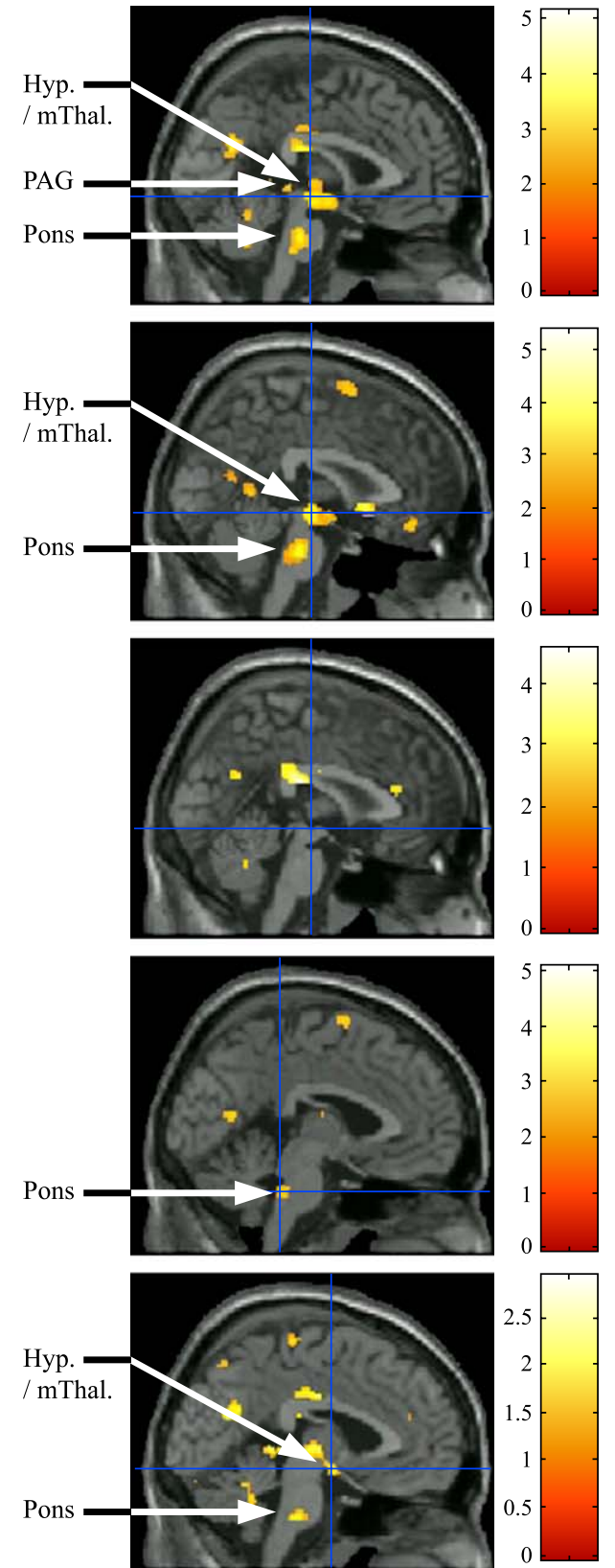

B. Effects of stimulus duration during pain

$(\mathrm{pa}-\mathrm{pb})$

C. Effects of stimulus duration during cold

$(\mathrm{ca}-\mathrm{cb})$

D. Interaction effect

$(\mathrm{pa}-\mathrm{pb})-(\mathrm{ca}-\mathrm{cb})$

A. Main effect of stimulus duration

$(p a+c a)-(p b+c b)$

E. Conjuction analysis

$(\mathrm{pa}-\mathrm{pb})$ and $(\mathrm{ca}-\mathrm{cb})$

Fig. 3. Areas that showed stimulus duration effects. The post hoc analysis based on $8 \mathrm{~mm}$ smoothed images has been used for this illustration to better delineate the different activations in the brainstem. (A) In the main effect of stimulus duration $[(\mathrm{pa}+\mathrm{ca})-(\mathrm{pb}+\mathrm{cb})]$ increased activity was observed in an area encompassing the hypothalamus (Hyp.) stretching back towards the PAG, the medial thalamus (m Thal.), and the pons. (B) The same areas showed increased activity for the stimulus duration effects for pain ( $\mathrm{pa}-\mathrm{pb}$ ). (C) No such significant findings were observed for the nonpainful control stimulation (ca - cb), although nonsignificant increases were observed in similar areas of the brainstem (see Table 2). (D) The interaction analysis [(pa $-\mathrm{pb})-(\mathrm{ca}-\mathrm{cb})]$ indicated that the stimulus duration effect was significantly greater for the painful conditions in the pons. This effect survived a masking with the main effect of stimulus duration contrast. (E) A conjunction analysis of $(\mathrm{pa}-\mathrm{pb})$ and $(\mathrm{ca}-\mathrm{cb})$ indicated that both the painful and the cold conditions contributed to the stimulus duration effect in the hypothalamus and the pons. The showed activity was thresholded at $P$ uncorrected $<0.005$. The activity is presented on an SPM99 template. 
brainstem nociceptive system and the cortical pain matrix, without a more constrained hypothesis, this must be considered as an explorative post hoc analysis.

\section{Results}

\section{Behavioural results}

\section{Visual analogue scale}

All subjects reported pain during all the noxious stimulations ( $p a$ and $\mathrm{pb}$; average pain intensity rating $=53.2 ; \mathrm{SD}=18.7 ; 0=$ no pain and $100=$ highest imaginable pain intensity rated after each 2 min stimulation), and none of the subjects reported pain during the cold stimulations (ca and $\mathrm{cb}$ ). Since the stimulation period continued for $2 \mathrm{~min}$ in both the conditions that were scanned during the first as well as the second minute, it was not possible to assess the pain ratings for the first and second minute of scanning respectively without undue interference with the repeatability. However, the behavioural aspects including pain rating for the different time periods during prolonged cold pressor test stimulation has previously been thoroughly studied (Rainville et al., 1992; Tassorelli et al., 1995).

\section{Galvanic skin response}

The GSR showed a habituation effect for the painful and control stimulation (Fig. 1B). The average GSR was 17.36 (SD 8.60) $\mu \mathrm{S}$ for ca, 14.95 (SD 7.20) $\mu \mathrm{S}$ for $\mathrm{cb}, 18.33$ (SD 9.74) $\mu \mathrm{S}$ for pa, and 15.29 (SD 10.18) $\mu \mathrm{S}$ for pb. A contrast analysis of a fix effect one-way ANOVA (repeated measurements) showed that there was a significant main effect of stimulus duration $(P=$ $0.021 ; F=9.5)$. This effect was significant for pain $(P=0.012 ; F=$ 12.7 ) but not for cold ( $P=0.12 ; F=3.2$ ). However, there was no significant difference in GSR between pain and cold $(P=0.78$; $F=0.084)$.

\section{Imaging results - contrast analysis}

\section{Main effect of pain}

Significant activations were observed bilaterally in the ACC and the thalamus during all painful conditions vs. all nonpainful conditions $[(\mathrm{pa}+\mathrm{pb})-(\mathrm{ca}+\mathrm{cb})$; Table 1; Fig. 2A]. The contralateral activations had higher $Z$ scores and larger activated areas than the ipsilateral activations. The activation in thalamus spread into the upper midbrain but no peak-activated voxel was observed in this region. Also, the contralateral midanterior insula showed increased activity. No activity was observed in the lateral pain system (S1 and S2).

A significant deactivation, that is, $[(\mathrm{ca}+\mathrm{cb})-(\mathrm{pa}+\mathrm{pb})]$, was observed in the anterior medial temporal lobe (MTL) or amygdala (Table 1; Fig. 2B). In the ipsilateral S1, deactivations were observed approximately in the somatotopic leg area and in the hand area, although there was no maximally deactivated voxel in the S1 hand area but a continuum of decreased activity stretching from the posterior parietal cortex (PPC). Finally, significant deactivations were observed in the temporopolar regions extending into the lateral orbitofrontal cortex bilaterally. The deactivation in the lateral orbitofrontal region was more pronounced in the left hemisphere.

Similar effects were observed for both the first $(\mathrm{pa}-\mathrm{ca}$ ) and second minute of pain $(\mathrm{pb}-\mathrm{cb})$, and there were no statistical differences between these contrasts. Due to lack of space, these effects are not presented in the present article.

\section{Main effect of stimulus duration}

A significant activation encompassed the hypothalamus and the pons during the first minute conditions vs. the second minute conditions $[(\mathrm{pa}+\mathrm{ca})-(\mathrm{pb}+\mathrm{cb})$; Table 1; Fig. 3A illustrates these activation in the post hoc $8 \mathrm{~mm}$ smoothed images]. This activity spread dorsally to regions encompassing the PAG and rostrally into the medial thalamus (with no regional maxima). No significant changes were observed in the second minute conditions vs. the first minute conditions $[(\mathrm{pb}+\mathrm{cb})-(\mathrm{pa}+\mathrm{ca})]$.

\section{Simple main effect of stimulus duration}

Significant activations were observed in the hypothalamus (with activity stretching into the PAG dorsally and the medial thalamus rostrally) and in the pons during the first minute condition vs. the second minute condition of pain $[(\mathrm{pa}-\mathrm{pb})$; Table 1; Fig. 3B illustrates these activation in the post hoc $8 \mathrm{~mm}$ smoothed images]. No significant changes were observed in the second minute condition vs. the first minute condition of pain ( $\mathrm{pb}-\mathrm{pa})$. No significant stimulus duration effects were observed in the cold conditions $[(\mathrm{ca}-\mathrm{cb})$ and $(\mathrm{cb}-\mathrm{ca})$; Fig. $3 \mathrm{C}$ illustrates this condition in the post hoc $8 \mathrm{~mm}$ smoothed images]. A closer examination disclosed that there were subsignificant tendencies of stimulus duration effect during (ca $-\mathrm{cb})$ in areas of the hypothalamus and PAG that overlapped with the effects in (pa $-\mathrm{pb})$.

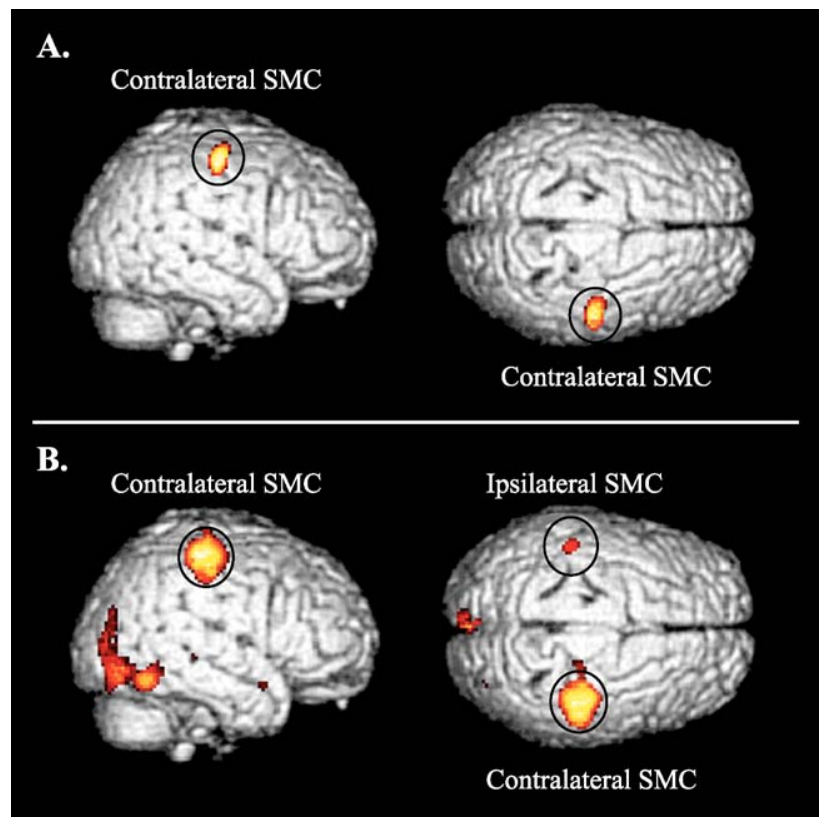

Fig. 4. The hypothalamus showed pain specific covariation with the sensory motor cortex (SMC) for the somatotopical hand area of the stimulated hand both during the first minute of stimulation (A) and during the second minute of stimulation (B). During the second minute of stimulation, the hypothalamus also covaried (pain-specifically) with the somatotopic hand area of the somatosensory cortex ipsilateral to the stimulation. The showed activity was thresholded at $Z=3.09$. The activity is presented on an SPM99 template. 
Table 3

Regions that covary with the activity in the hypothalamus in the post hoc regression analysis

\begin{tabular}{|c|c|c|c|c|}
\hline & $\begin{array}{l}\text { Contralateral } \\
(X Y Z)\end{array}$ & $Z$ value & $\begin{array}{l}\text { Ipsilateral } \\
(X Y Z)\end{array}$ & $Z$ value \\
\hline \multicolumn{5}{|l|}{ First minute of cold (ca) } \\
\hline \multicolumn{5}{|l|}{ Positive covariation } \\
\hline \multirow[t]{2}{*}{ PAG/midbrain } & $0-34-40$ & 3.28 & & \\
\hline & $2-38-38$ & 3.27 & & \\
\hline \multicolumn{5}{|l|}{ Negative covariation } \\
\hline \multirow[t]{3}{*}{ S1 } & $68-1022$ & 3.59 & $-44-2260$ & 4.58 \\
\hline & $54-1656$ & 3.42 & $-36-2266$ & 4.24 \\
\hline & $12-2468$ & 3.42 & $-2-3468$ & 3.22 \\
\hline \multicolumn{5}{|c|}{ Second minute of cold $(\mathrm{cb})$} \\
\hline \multicolumn{5}{|l|}{ Negative covariation } \\
\hline \multirow[t]{5}{*}{ S1 } & $0-2248$ & 5.0 & $-20-2966$ & 5.24 \\
\hline & $50-2056$ & 4.42 & $-28-3662$ & 4.75 \\
\hline & $20-2470$ & 4.32 & $-38-4060$ & 4.74 \\
\hline & $0-2870$ & 4.31 & $-46-2060$ & 4.57 \\
\hline & $42-3456$ & 4.01 & & \\
\hline Ant MTL/amygdala & & & $-24-12-26$ & 4.07 \\
\hline \multicolumn{5}{|c|}{ Second minute of pain $(\mathrm{pb})$} \\
\hline \multicolumn{5}{|c|}{ Positive covariation } \\
\hline $\mathrm{S} 1$ & $56-3042$ & 3.15 & & \\
\hline SSA & & & $-46-4022$ & 3.57 \\
\hline \multirow[t]{4}{*}{ Midanterior insula } & $40-108$ & 4.45 & $-320-12$ & 3.57 \\
\hline & $28-618$ & 3.76 & & \\
\hline & 241412 & 3.71 & & \\
\hline & $3624-6$ & 3.37 & & \\
\hline $\begin{array}{l}\text { Ant MTL/amygdala } \\
\text { pa vs. ca }\end{array}$ & $-26-10-30$ & 3.39 & & \\
\hline S1 & $54-1652$ & 3.98 & & \\
\hline \multicolumn{5}{|l|}{ pb vs. cb } \\
\hline \multirow[t]{2}{*}{$\mathrm{S} 1$} & $42-2456$ & 3.98 & $-46-3050$ & 3.49 \\
\hline & $4-2448$ & 3.97 & & \\
\hline PAG/midbrain & & & $-2-34-12$ & 3.3 \\
\hline Ant MTL/amygdala & & & $-26-20-28$ & 4.41 \\
\hline
\end{tabular}

The contrast analyses between regressions pa vs. ca and pb vs. cb are shown to find pain-specific covariations between the hypothalamus and regions of the cortical pain network. Ant MTL = anterior medial temporal lobe; $\mathrm{PAG}=$ periaqueductal grey; $\mathrm{S} 1$ = primary somatosensory cortex; $\mathrm{SSA}=$ somatosensory association areas.

\section{Interaction analysis}

The interaction analysis $[(\mathrm{pa}-\mathrm{pb})-(\mathrm{ca}-\mathrm{cb})]$ disclosed that the observed stimulus duration effect in the pons was significantly stronger in pain as compared to cold after masking the results in the main effect of stimulus duration (Table 1; Fig. 3D illustrates this activation in the post hoc $8 \mathrm{~mm}$ smoothed images). The reverse interaction $[(\mathrm{pb}-\mathrm{pa})-(\mathrm{cb}-\mathrm{ca})]$ did not reveal any significant results.

\section{Post hoc analysis of $8 \mathrm{~mm}$ smoothed images}

This analysis showed a similar activation pattern in the brainstem as in the main analysis (Table 2). However, the stimulus duration-dependent areas in the brainstem could be better separated and are shown in Fig. 3. Also, stimulus duration-dependent local maxima were observed in the medial thalamus bilaterally both in the pain and in the cold conditions. The conjunction analysis showed that both pain and cold contributed to stimulus duration effects in the hypothalamus, pons, and medial thalamus regions (Table 2 and Fig. 3E).

\section{Imaging results - post hoc regression analysis}

\section{Areas covarying with hypothalamic activity}

During ca and cb, the activity in the voxel representing the hypothalamus covaried negatively with vast regions of the primary sensory motor cortex (Table 3). It was not possible to establish whether the maximum activation was in the S1 or M1, but it included the postcentral gyrus at all levels. There was no indication that the negative regression was more pronounced for the somatotopic site of the stimulated hand. On the contrary, more voxels covaried with the ipsilateral hemisphere. During cb, there was also a negative regression with the left anterior MTL or amygdala; and during ca, a positive regression was observed with the PAG or midbrain. During pb, voxels that were positively regressed on the hypothalamic activity were observed in the primary S1 for the stimulated hand, bilaterally in the midanterior insula, in the contralateral MTL or amygdala, and in the ipsilateral somatosensory association areas (Table 3 ). No significant regression with the hypothalamic activity was observed during pa.

The hypothalamic activity covaried significantly more with the primary sensory motor cortex for the stimulated hand during pa vs. ca (Table 3; Fig. 4A). The position was possibly more in the precentral gyrus but extended clearly into the postcentral gyrus. A similar difference in regressions with the hypothalamic activity was observed in the somatotopic sensory motor region for the stimulated hand during the second minute (pb vs. cb) (Table 3; Fig. 4B). The maximally regressed voxel was now clearly observed in the

Table 4

Regions that covary with the activity in the pons in the post hoc regression analysis

\begin{tabular}{|c|c|c|c|c|}
\hline & $\begin{array}{l}\text { Contralateral } \\
\left(\begin{array}{lll}X & Y & Z\end{array}\right)\end{array}$ & $Z$ value & $\begin{array}{l}\text { Ipsilateral } \\
(X Y Y Z)\end{array}$ & $Z$ value \\
\hline \multicolumn{5}{|c|}{ First minute of cold (ca) } \\
\hline \multicolumn{5}{|c|}{ Positive covariation } \\
\hline PAG/midbrain & & & $-8-28-8$ & 4.52 \\
\hline \multicolumn{5}{|c|}{ First minute of pain (pa) } \\
\hline \multicolumn{5}{|c|}{ Positive covariation } \\
\hline Insula/S2 & $44-2622$ & 3.35 & & \\
\hline \multicolumn{5}{|c|}{ Second minute of pain $(\mathrm{pb})$} \\
\hline \multicolumn{5}{|c|}{ Positive covariation } \\
\hline Insula/S2 & $44-3022$ & 6.16 & $-40-3224$ & 3.27 \\
\hline Midanterior insula & $\begin{array}{l}42-14-2 \\
42164\end{array}$ & $\begin{array}{l}4.99 \\
4.32\end{array}$ & -301610 & \\
\hline $\mathrm{ACC} / \mathrm{vmPFC}$ & $\begin{array}{l}142832 \\
04612\end{array}$ & $\begin{array}{l}5.39 \\
5.16\end{array}$ & -43224 & 5.98 \\
\hline $\mathrm{Obfc} / \mathrm{Tpc}$ & $2438-10$ & 5.22 & $\begin{array}{l}-2836-4 \\
-1826-10\end{array}$ & $\begin{array}{l}6.35 \\
5.89\end{array}$ \\
\hline $\begin{array}{l}\text { pa vs. ca } \\
\text { Insula/S2 }\end{array}$ & $46-2822$ & 3.48 & & \\
\hline pb vs. cb & & & & \\
\hline Insula/S2 & $46-3022$ & 4.31 & & \\
\hline $\mathrm{ACC}$ & $\begin{array}{l}142834 \\
25210\end{array}$ & $\begin{array}{l}3.11 \\
3.72\end{array}$ & -63624 & 3.78 \\
\hline Midanterior insula & $\begin{array}{lll}38 & 16 & 10 \\
46 & 14 & 2\end{array}$ & $\begin{array}{l}3.68 \\
3.14\end{array}$ & -321610 & 3.68 \\
\hline $\mathrm{Obfc} / \mathrm{Tpc}$ & $2440-4$ & 3.57 & $-2634-4$ & 4.16 \\
\hline
\end{tabular}

The contrast analyses between regressions pa vs. ca and pb vs. cb are shown to find pain-specific covariations between the pons and regions of the cortical pain network. $\mathrm{ACC}=$ anterior cingulate cortex; $\mathrm{PAG}=$ periaqueductal grey; Obfc $=$ orbitofrontal cortex; $\mathrm{S} 2=$ secondary somatosensory cortex; $\mathrm{Tpc}=$ temporopolar cortex; $\mathrm{vmPFC}=$ ventromedial prefrontal cortex. 


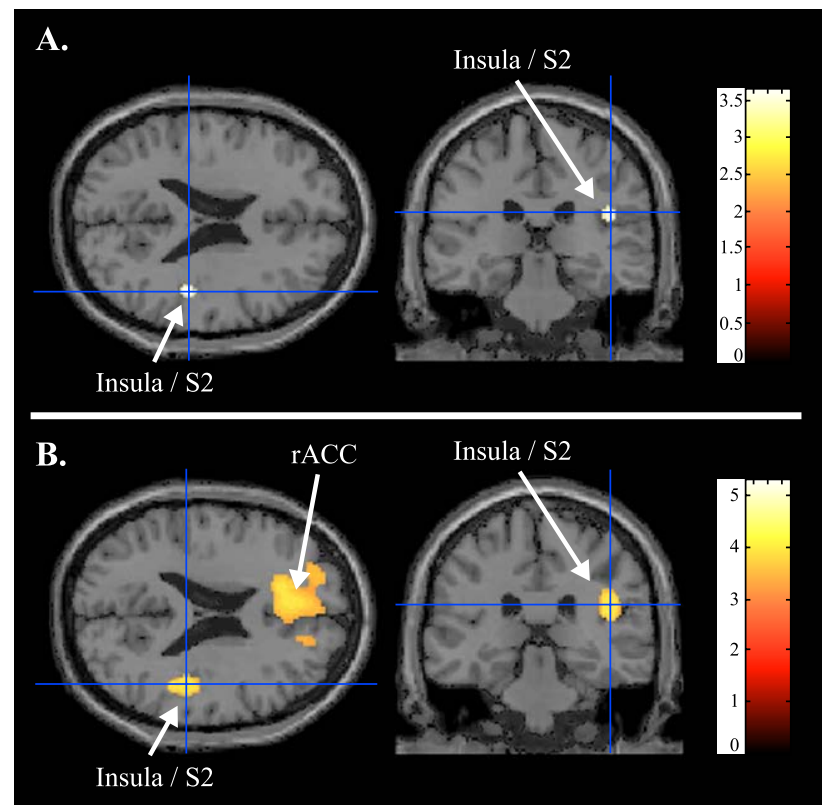

Fig. 5. The pons covaried pain-specifically with the posterior insula or S2 both during the first (A) and during the second (B) minute of stimulation. In (B) areas in the rostral, anterior cingulate cortex (rACC) also covaried painspecifically with the pons. The showed activity was thresholded at $Z=3.09$. The activity is presented on an SPM99 template.

postcentral gyrus. Moreover, the hypothalamus covaried significantly more during pb vs. cb also in ipsilateral primary sensory motor hand region, in the PAG or midbrain, and in the left anterior MTL or amygdala.

\section{Areas covarying with activity in pons}

During ca, the activity in the pons covaried positively with the PAG or midbrain (Table 4). During pa, the pons activity covaried significantly with a region involving the posterior insula and S2. This regression was significantly more pronounced during the first minute of pain as compared to the first minute of cold (pa vs. ca) (Table 4; Fig. 5A).

No activity covaried significantly with the pons during cb. During pb, a similar but bilateral regression was observed in the posterior insula or S2 (Table 4). Moreover, the pons was positively regressed with the midanterior insula, the rostral ACC, and temporopolar or orbitofrontal regions bilaterally during $\mathrm{pb}$. Significant differences in the regressions with the activity in the pons during $\mathrm{pb}$ vs. cb were observed in all regions above except for the ipsilateral insula or S2 region (Table 4; Fig. 5B).

\section{Discussion}

The main finding in this study showed that several regions in the brainstem were significantly more involved in the initial phase of the tonic painful stimulation as compared to the later phase (Fig. 3 ; Table 1). These rCBF effects were mirrored by a habituation in GSR, suggesting a habituation of sympathetic outflow (Fig. 1B). Since it has been shown that brainstem structures are involved in autonomic processing (Loewy, 1990, 1991), it seems reasonable to suppose that these regions may have participated in the observed GSR response. Especially several brainstem regions have shown a specific involvement of both autonomic and nociceptive processing (Aston-Jones et al., 1999, Craig and Dostrovsky, 1999). The PET data supported that there is a special role for these regions in pain processing, that is, both the interaction analysis and the regression analysis indicated that this brainstem activity was specific for pain.

We chose not to measure the stimulus duration effect on pain ratings in this study because this self-evaluating process would have interfered with the $\mathrm{rCBF}$ habituation effects that were our main interest. The behavioural stimulus duration effects for the cold pressor test, including pain ratings, have thoroughly been studied previously (e.g., Rainville et al., 1992; Tassorelli et al., 1995). These studies show that the pain intensity rating increases from the onset of the stimulation and levels off after approximately 2 min. Thus, we know that although the pain rating increases during the stimulus prolongation, the brainstem activity and the GSR were most expressed during the first minute. This indicates that the brainstem response to nociceptive input correlates with autonomic activity but not with the conscious experience of pain.

Although not activated in the main effect of pain in this study (or several other functional imaging studies), increased activity have been shown in the brainstem and the hypothalamus during traumatic painful event that included an intense emotional experience with concomitant autonomic and somatic outflow (Hsieh et al., 1995). As in the present study, the brainstem activity was coupled with a highly increased autonomic output during pain.

An fMRI study observed increased activity in the PAG during initial pain processing but decreased activity in a similar region during a later phase of the noxious stimulation (Becerra et al., 2001). In that study, also a tonic stimulation was used with the duration of $25 \mathrm{~s}$. However, the drawback was that the difference between the late and the initial phase was not statistically tested. Thus, although the findings are in line with our study, the data are not conclusive.

In contrast to the present study, Casey et al. (2001) found no increase of activity in the brainstem during the initial vs. late noxious stimulation as measured with PET. A crucial difference between the studies was that they used phasic stimulation while we used tonic stimulation. Since brainstem structures such as locus coeruleus react to novel stimuli and noxious stimuli (Aston-Jones et al., 1999), each novel noxious input of the phasic stimulation could potentially reactivate the brainstem both during the initial as well as during the late phase. Thus, contrary to the tonic stimulation, less signs of habituation would be expected.

An event-related fMRI study of brief laser evoked pain has showed activation of the upper brainstem in a region that was interpreted as the red nucleus (Bingel et al., 2002). However, this study has specifically avoided habituation effects and can therefore not be directly compared with the present study. Potentially, eventrelated fMRI may be a better method to study these effects in subcortical structures because of a better spatial and temporal resolution (Bingel et al., 2002), although there is a risk of condition-related movement artefacts in fMRI studies of the brainstem.

Sympathetic responses such as GSR are well-established correlates of arousal (Critchley et al., 2000b, 2001a,b,c; Tracy et al., 2000) and depend on networks in the brainstem (Loewy, 1990; Raine et al., 1991). In line with this suggestion, the GSR and the heart rate have been shown to correlate with activity in the brainstem during arousal (Critchley et al., 2000a; Tracy et al., 2000). Also, a correlation has been shown between alert states and 
the activity in the brainstem during wakefulness, anesthesia, and relaxation (Fiset et al., 1999; Hofle et al., 1997; Paus, 2000; Paus et al., 1997; Tracy et al., 2000). Arousal is also central in nociceptive processing to initiate a rapid response in a potential life-threatening situation (Jäning, 1995).

Increased autonomic outflow during acute pain may also be viewed as a part of the active fear or defense reaction during the circa-strike phase that may be initiated by ascending noxious input via the dorsolateral PAG (Fanselow, 1994). This has been shown in experimental animals, but similar states have also been shown in human subjects (Lang et al., 2000). These processes are probably not induced only by the PAG but by a brainstem network, for example, the PAG is known to work in concert with the rostral ventromedial medulla and regions in the pons during different types of analgesia (Fields and Basbaum, 1999). This could explain the coactivation with the lower pons observed in the stimulus duration effect of pain $(\mathrm{pa}-\mathrm{pb})$ and in the interaction analysis $(\mathrm{pa}-\mathrm{pb})-(\mathrm{ca}-\mathrm{cb})$.

Although the control condition was neither painful nor threatening, a habituation effect of the sympathetic response was observed in the present data set. Moreover, there were no significant differences between the painful and the control states in the GSR although such effects have previously been reported (Bromm and Scharein, 1982; Dowling, 1982, 1983; Gracely, 1999; Jäning, 1995; Lovallo, 1975). Possibly, the lack of such effects depends on the small number of subjects and a variable response. Also the control condition carries some initial arousal that declines with time, indicated by the subsignificant stimulus duration effect in the hypothalamus and the pons, and the results of the conjunction analysis. However, there were several findings, which suggested that the brainstem processing was different during the noxious as compared with the control condition. Significant stimulus duration effect in the hypothalamus and the pons was only observed in the general analysis (including both pain and control conditions) and during painful stimulation (Fig. 3; Table 1). Also, the stimulus duration effect was significantly more expressed in the pons during the painful conditions (Fig. 3D; Table 1). This suggests that the habituation effects were different during pain as compared to nonpainful cold. To further test whether the areas, which showed habituation effects and possibly are involved in arousal reactions, may be specifically coupled to the noxious event per se, we performed a regression analysis for the two regions showing stimulus duration effects. Although this was an explorative post hoc analysis, it indicated that there is a general interaction between the brainstem and the cortical pain matrix that was specific to pain. This functional relationship may be interpreted as that both networks receive the same (noxious) input or that they interact during the processing of nociceptive input. In any case, it indicates that the processing in these areas is nociceptive specific.

The hypothalamus activity covaried more with the primary sensory-motor cortex for the stimulated hand, and the pons covaried more with the posterior insula during the pain as compared with the cold conditions. The findings were observed both for the first (Figs. 4A and 5A; Tables 3 and 4) and for the second minute of stimulation (Figs. 4B and 5B; Tables 3 and 4), that is, in two different sets of scans. During the second minute of stimulation, a similar relationship was also observed between the pons and the orbitofrontal cortex and between the pons and the rostral ACC. PET cannot resolve which brainstem nuclei contribute to the stimulus duration effects. However, two candidate regions are the locus coeruleus and the parabrachial nucleus, which are both involved in processing nociceptive signals, autonomic and arousal response, and ascending control (Aston-Jones et al., 1999; Craig and Dostrovsky, 1999). The functional relation between the pons and the posterior insula is in line with the known neural projections between these regions (Craig and Dostrovsky, 1999) and the involvement of the posterior insula in autonomic processing (Cechetto and Saper, 1990). However, cortical regions such as the ACC may also modulate the brainstem activity during pain possibly through the endogenous opioid systems (Petrovic et al., 2002a; Vogt et al., 1993).

No structures in the medial pain system showed any stimulus duration effects. This in line with a relatively constant pain rating during prolonged cold pressor test (Rainville et al., 1992). Similarly, Bromm and Scharein (1982) showed that while pain ratings and evoked potentials did not show any change over time during several sessions of painful electrical stimulation, the GSR showed decreasing responses. These studies indicate that structures that process the pain perception per se maintain their activity while structures that are more directly involved in arousal and sympathetic outflow due to pain habituate. Two previous functional imaging studies have shown even an increased activity in the cortical pain network during prolonged pain (Becerra et al., 2001; Casey et al., 2001). Although, there was no such statistical difference between late and initial pain processing in the present study, the activity in the ACC had higher $Z$ values and was more extensive during late pain processing.

We did not observe any activation of the lateral pain system due to pain either in the first or in the second minute of stimulation. Thus, this study cannot indicate whether stimulus duration may alter the activity in the lateral pain system, although it may be suggested that the parietal (somatosensory) regions are preferentially involved in the initial pain response (Backonja et al., 1991). There are several possible reasons why no increased net activity was observed in the lateral pain system in the present study (see further Petrovic et al., 2002b). However, the S1 covaried with regions involved in pain processing specifically during the painful stimulation, indicating that the lateral pain system is involved in pain processing also in this study (Petrovic et al., 2002b). In the present study, a deactivation was observed in the ipsilateral primary somatosensory cortex for the hand and the foot during pain, that is, outside the somatotopic region for the stimulated hand area. A similar result of no increased net activity in the somatotopic S1 area for the stimulated hand combined with a decreased activity in the ipsilateral S1 has been observed previously both for painful stimulation (Peyron et al., 1999) and tickle (Carlsson et al., 2000).

\section{Conclusion}

This study showed significant effects of stimulus duration on the $\mathrm{rCBF}$ activity in brainstem areas encompassing the PAG, hypothalamus, and pons, as well as stimulus duration-dependent habituation of galvanic skin response. The rCBF changes due to stimulus duration were significantly more pronounced for pain as compared to cold in pons. The study also shows that the activity in the regions sensitive to stimulus duration had pain-specific functional relations with cortical areas involved in pain processing. Thus, this study indicates that the brainstem is specifically involved in the initial supraspinal processing and response to 
noxious stimulation consistent with the evolutionary demand for a fast response in a potentially life-threatening situation.

\section{Acknowledgments}

We gratefully acknowledge the assistance of all members in the PET unit. Financial support was received from The Petrus and Augusta Hedlund Foundation, Swedish Research Councils (8246), and The Karolinska Institute.

\section{References}

Aston-Jones, G., Rajkowski, J., Cohen, J., 1999. Role of locus coeruleus in attention and behavioral flexibility [Review]. Biol. Psychiatry 46, $1309-1320$.

Backonja, M., Howland, E.W., Wang, J., Smith, J., Salinsky, M., Cleeland, S.C., 1991. Tonic changes in alpha power during immersion of the hand in cold water. Electroenceph. Clin. Neurophysiol. 79, 192-203.

Becerra, L.R., Breiter, H.C., Wise, R., Gonzalez, R.G., Borsook, D., 2001. Reward circuitry activation by noxious thermal stimuli. Neuron 32, 927-946.

Berridge, M.S., Cassidy, E.H., Terris, A.H., 1990. A routine, automated synthesis of oxygen-15-labeled butanol for positron tomography. J. Nucl. Med. 31, 1727-1731.

Bingel, U., Quante, M., Knab, R., Bromm, B., Weiller, C., Buchel, C., 2002. Subcortical structures involved in pain processing: evidence from single-trial fMRI. Pain 99, 313-321.

Blanchard, R.J., Blanchard, D.C., Rodgers, J., Weiss, S.M., 1990. The characterization and modelling of antipredator defensive behavior [Review]. Neurosci. Biobehav. Rev. 14, 463-472.

Bolles, R.C., 1970. Species-specific defence reactions and avoidance learning. Psychol. Rev. 77, 32-48.

Bromm, B., Scharein, E., 1982. Response plasticity of pain evoked reactions in man. Physiol. Behav. 28, 109-116.

Carlsson, K., Petrovic, P., Skare, S., Petersson, K.M., Ingvar, M., 2000. Tickling expectations: neural processing in anticipation of a sensory stimulus. J. Cogn. Neurosci. 12 (4), 691-703.

Casey, K.L., Morrow, T.J., Lorenz, J., Minoshima, S., 2001. Temporal and spatial dynamics of human forebrain activity during heat pain: analysis by positron emission tomography. J. Neurophysiol. 85, 951-959.

Cechetto, D.F., Saper, C.B., 1990. Role of the cerebral cortex in autonomic functioning. In: Loewy, A.D., Spyer, K.M. (Eds.), Central Regulation of Autonomic Functions. Oxford Univ. Press, New York, pp. 208-223.

Craig, A.D., Dostrovsky, J.O., 1999. Medulla to thalamus. In: Wall, P.D., Melzack, R. (Eds.), Textbook of Pain. Churchill Liningstone, Edinburgh, pp. 183-214.

Critchley, H.D., Corfield, D.R., Chandler, M.P., Mathias, C.J., Dolan, R.J., 2000a. Cerebral correlates of autonomic cardiovascular arousal: a functional neuroimaging investigation in humans. J. Physiol. $1,259-270$.

Critchley, H.D., Elliott, R., Mathias, C.J., Dolan, R.J., 2000b. Neural activity relating to generation and representation of galvanic skin conductance responses: a functional magnetic resonance imaging study. J. Neurosci. 20, 3033-3040.

Critchley, H.D., Mathias, C.J., Dolan, R.J., 2001a. Neural activity in the human brain relating to uncertainty and arousal during anticipation. Neuron 29, 537-545.

Critchley, H.D., Mathias, C.J., Dolan, R.J., 2001b. Neuroanatomical basis for first- and second-order representations of bodily states. Nat. Neurosci. 4, 207-212.

Critchley, H.D., Melmed, R.N., Featherstone, E., Mathias, C.J., Dolan, R.J., 2001c. Brain activity during biofeedback relaxation: a functional neuroimaging investigation. Brain 124, 1003-1012.
Dowling, J., 1982. Autonomic indices and reactive pain reports on the McGill pain questionnaire. Pain 14, 387-392.

Dowling, J., 1983. Autonomic measures and behavioral indices of pain sensitivity. Pain 16, 193-200.

Fanselow, M.S., 1982. The postshock activity burst. Anim. Learn. Behav. $10,448-454$.

Fanselow, M.S., 1994. Neural organization of the defensive behavior system responsible for fear. Psychon. Bull. Rev. 1, 429-438.

Fanselow, M.S., Sigmundi, R.A., 1986. Species-specific danger signals, endogenous opioid analgesia, and defensive behavior. J. Exp. Psychol, Anim. Behav. Processes 12, 301-309.

Fields, H., Bausbaum, A., 1999. Central nervous system mechanisms of pain modulation. In: Wall, P., Melzack, R. (Eds.), Textbook of Pain. Churchill Livingstone, pp. 309-329.

Fiset, P., Paus, T., Daloze, T., Plourde, G., Meuret, P., Bonhomme, V., HajjAli, N., Backman, S.B., Evans, A.C., 1999. Brain mechanisms of propofol-induced loss of consciousness in humans: a positron emission tomographic study. J. Neurosci. 19, 5506-5513.

Friston, K., 1994. Functional and effective connectivity: a synthesis. Hum. Brain Map. 2, 56-78.

Friston, K.J., Holmes, A.P., Worsley, K.J., Poline, J.-P., Frackowiak, R.S.J., 1995. Statistical parametric maps in functional imaging: a general linear approach. Hum. Brain Mapp. 2, 189-210.

Friston, K.J., Buechel, C., Fink, G.R., Morris, J., Rolls, E., Dolan, R.J., 1997. Psychophysiological and modulatory interactions in neuroimaging. NeuroImage 6, 218-229.

Genovese, C.R., Lazar, N.A., Nichols, T., 2002. Thresholding of statistical maps in functional neuroimaging using the false discovery rate. NeuroImage $15,870-878$.

Gracely, R.H., 1999. Studies of pain in human subjects. In: Wall, P.D., Melzack, R. (Eds.), Textbook of Pain. Churchill Liningstone, Edinburgh, pp. 385-407.

Hofle, N., Paus, T., Reutens, D., Fiset, P., Gotman, J., Evans, A.C., Jones, B.E., 1997. Regional cerebral blood flow changes as a function of delta and spindle activity during slow wave sleep in humans. J. Neurosci. 17, $4800-4808$.

Hsieh, J.C., Ståhle-Bäckdahl, M., Hägermark, Ö., Stone-Elander, S., Rosenquist, G., Ingvar, M., 1995. Traumatic nociceptive pain activates the hypothalamus and the periaqueductal gray: a positron emission tomography study. Pain 64, 303-314.

Ingvar, M., 1999. Pain and functional imaging [Review]. Philos. Trans. R. Soc. Lond., B Biol. Sci. 354, 1347-1358.

Ingvar, M., Eriksson, L., Greitz, T., Stone-Elander, S., Dahlbom, M., Rosenqvist, G., af Trampe, P., von Euler, C.V., 1994. Methodological aspects of brain activation studies: cerebral blood flow determined with [15O] butanol and positron emission tomography. J. Cereb. Blood Flow Metab. 14, 628-638.

Jäning, W., 1995. The sympathetic nervous system in pain [Review]. Eur. J. Anaesthesiol., Suppl. 10, 53-60.

Lang, P.J., Davis, M., Ohman, A., 2000. Fear and anxiety: animal models and human cognitive psychophysiology [Review]. J. Affect. Disord. 61, $137-159$.

Loewy, A.D., 1990. Central autonomic pathways. In: Loewy, A.D., Spyer, K.M. (Eds.), Central Regulation of Autonomic Functions. Oxford Univ. Press, New York, pp. 88-103.

Loewy, A.D., 1991. Forebrain nuclei involved in autonomic control [Review]. Prog. Brain Res. 87, 253-268.

Lovallo, W., 1975. The cold pressor test and autonomic function: a review and integration. Psychophysiology 12, 268-282.

Parvizi, J., Damasio, A., 2001. Consciousness and the brainstem. Cognition $79,135-160$.

Paus, T., 2000. Functional anatomy of arousal and attention systems in the human brain [Review]. Prog. Brain Res. 126, 65-77.

Paus, T., Zatorre, R.J., Hofle, N., Caramanos, Z., Gotman, J., Petrides, M., Evans, A.C., 1997. Time-related changes in neural systems underlying attention and arousal during the performance of an auditory vigilance task. J. Cogn. Neurosci. 9, 392-408. 
Petrovic, P., Petersson, K.M., Ghatan, P.H., Stone-Elander, S., Ingvar, M., 2000. Pain-related cerebral activation is altered by a distracting cognitive task. Pain 85, 19-30.

Petrovic, P., Kalso, E., Petersson, K.M., Ingvar, M., 2002a. Placebo and opioid analgesia-imagine a shared neuronal network. Science 295 , $1737-1740$

Petrovic, P., Petersson, K.M., Hansson, P., Ingvar, M., 2002b. A regression analysis study of the primary somatosensory cortex during pain. NeuroImage 16, 1142-1150.

Peyron, R., Garcia-Larrea, L., Gregoire, M.C., Costes, N., Convers, P., Lavenne, F., Mauguiere, F., Michel, D., Laurent, B., 1999. Haemodynamic brain responses to acute pain in humans: sensory and attentional networks. Brain 122, 1765-1780.

Price, D.D., 2000. Psychological and neural mechanisms of the affective dimension of pain [Review]. Science 288, 1769-1772.

Raine, A., Reynolds, G.P., Sheard, C., 1991. Neuroanatomical correlates of skin conductance orienting in normal humans: a magnetic resonance study. Psychophysiology 28, 548-558.

Rainville, P., Feine, J.S., Bushnell, M.C., Duncan, G.H., 1992. A psychophysical comparison of sensory and affective responses to four modalities of experimental pain. Somatosens. Motor Res. 9, $265-277$.

Talairach, J., Tournoux, P., 1988. Co-Planar Stereotaxic Atlas of the Human Brain. Thieme Verlag, Georg, Stuttgart.

Tassorelli, C., Micieli, G., Osipova, V., Rossi, F., Nappi, G., 1995. Pupillary and cardiovascular responses to the cold-pressor test. J. Auton. Nerv. Syst. 55, 45-49.

Timberlake, W., 1993. Behavior systems and reinforcement: an integrative approach [Review]. J. Exp. Anal. Behav. 60, 105-128.

Tracy, J.I., Mohamed, F., Faro, S., Tiver, R., Pinus, A., Bloomer, C., Pyrros, A., Harvan, J., 2000. The effect of autonomic arousal on attentional focus. NeuroReport 11, 4037-4042.

Vogt, B.A., Sikes, R.W., Vogt, L.J., 1993. Anterior cingulate cortex and the medial pain system. In: Vogt, B.A., Gabriel, M. (Eds.), Neurobiology of Cingulate Cortex and Limbic Thalamus: A Comprehensive Handbook. Birkhäuser, Boston, MA, pp. 313-344.

Wienhard, K., Dahlbom, M., Eriksson, L., Michel, C., Bruckbauer, T., Pietrzyk, U., Heiss, W.D., 1994. The ECAT EXACT HR: performance of a new high resolution positron scanner. J. Comput. Assist. Tomogr. $18,110-118$ 